\title{
Flutuação populacional e controle de pragas: estudos de caso com pragas
}

\section{de arroz irrigado}

\author{
Eduardo Rodrigues Hickel' , Douglas George Oliveira², Domingos Sávio Eberhardt e Rene Kleveston ${ }^{4}$
}

\begin{abstract}
Resumo - Os estudos de flutuação populacional são muito importantes para o controle de pragas, pois fornecem informações fundamentais sobre quando e em que intensidade determinado organismo nocivo pode surgir nas lavouras, propiciando, assim, uma maior exatidão na aplicação de medidas de controle. A flutuação populacional da bicheira-da-raiz (Oryzophagus oryzae), do percevejo-do-grão (Oebalus spp.) e da lagarta-boiadeira (Nymphula spp.) em lavouras de arroz irrigado foram relacionadas à prática desse cultivo. Para essas espécies, medidas de controle podem ser planejadas e implementadas com base nos estudos de flutuação populacional.
\end{abstract}

Termos para indexação: monitoramento; dinâmica populacional; Oryzophagus oryzae; Oebalus spp.; Nymphula spp.

\section{Population fluctuation and pest control: studies with irrigated rice pests}

\begin{abstract}
Population fluctuation studies are very important for pest control, since they provide fundamental information on when and in what intensity a harmful organism can arise in crops, thus providing a greater accuracy in the application of control measures. The population fluctuation of the South American rice water weevil (Oryzophagus oryzae), of the rice stink bug (Oebalus spp.), and of the rice caseworm (Nymphula spp.) in irrigated rice fields were related to the crop management. For these species, control measures can be planned and implemented based on population fluctuation studies.
\end{abstract}

Index terms: monitoring; population dynamics; Oryzophagus oryzae; Oebalus spp.; Nymphula spp.

\section{Introdução}

As variações verificadas na ocorrência dos organismos vivos há muito recebem a atenção dos estudiosos de entomologia agrícola e são foco dos estudos de flutuação populacional (HICKEL et al., 2007). Para a produção agrícola, esses estudos fornecem informações fundamentais sobre quando e em que intensidade determinado organismo nocivo pode surgir nas lavouras, propiciando, assim, uma maior exatidão na aplicação das medidas de controle (LOGAN \& ALLEN, 1992).

Uma característica peculiar dos estudos de flutuação populacional é que o tempo, diretamente, não determina o número de indivíduos da população. O tempo sempre avança, ao passo que a população oscila para mais ou para menos. Assim, a visualização da variação do número de indivíduos no tempo não traduz as reais causas da varia- ção populacional (HICKEL et al., 2007). Outra característica, é que as mesmas tendências na flutuação populacional são verificadas em locais com condições ambientais semelhantes (POLTRONIERI et al., 2008), de modo que é possível fazer extrapolações regionais a partir de estudos locais.

Os estudos de caso apresentados a seguir têm por base o monitoramento de pragas do arroz irrigado com armadiIhas luminosas, executado desde a safra 2007/2008 na Estação Experimental da Epagri (EEI), em Itajaí, SC, e no período das safras de 2012/2013 a 2015/2016 no Centro de Treinamento da Epagri em Araranguá, SC (Cetrar). Convém salientar que as linhas médias apresentadas (onze safras em Itajaí e quatro em Araranguá) tendem a reduzir a amplitude das oscilações populacionais, porém indicam com maior precisão os períodos de ocorrência dos indivíduos.

Assim, o objetivo é analisar esses períodos, relacionando-os com a prática de cultivo do arroz irrigado, para orientar sobre as estratégias de controle, especialmente a racionalização do controle químico.

\section{Estudo de caso 1: bicheira- da-raiz, Oryzophagus oryzae (Costa Lima) (Coleoptera: Curculionidae)}

$\mathrm{Na}$ flutuação populacional de adultos, ressaltam-se dois momentos importantes na coleta de indivíduos (Figura 1). O primeiro está em meados de outubro e reflete a movimentação de adultos dos locais de hibernação para as lavouras (visto que a armadilha luminosa captura insetos em voo). O segundo momento vai de meados de dezembro ao final de fevereiro e reflete o retorno dos adultos das lavouras para os locais de hibernação. Em média, a ocorrência 
de adultos em meados de outubro é bem inferior àquela verificada a partir de meados de dezembro (Figura 1). Isso mostra que, embora a população que infesta as lavouras seja relativamente baixa, ela tem grande potencial de multiplicação (HICKEL et al., 2013).

Em Araranguá, há dois picos populacionais na época de abandono das lavouras (Figura 1), e isso talvez resulte da prática do cultivo orgânico no Cetrar, cujas lavouras são semeadas no final do período de plantio (novembro) (Tabela 1). Assim, o primeiro pico corresponderia à população gerada nas lavouras vizinhas (semeadas mais cedo), e o segundo pico à população gerada na própria área do Cetrar.

O momento de maior ocorrência de larvas (linha verde) vai do início de novembro a meados de dezembro e coincide com a redução da ocorrência de adultos nas lavouras (Figura 1). Cabe ressaltar que, mesmo que o monitoramento de larvas tenha sido executado há mais de 38 anos, ele ainda se adéqua à flutuação populacional de adultos nos dias de hoje.

Esses momentos revelam que até o início de outubro haverá pouca chance de se ter lavouras infestadas por bicheira-da-raiz (larvas). A saída dos adultos dos locais de hibernação não depende de que haja lavouras plantadas, mas do fotoperíodo, da temperatura e, provavelmente, da pressão atmosférica, cujos limiares só são atingidos em meados de outubro (HICKEL et al., 2013). Dessa forma, não se justifica aplicar inseticidas para controle da bicheira-da-raiz antes de meados de outubro. Também não adianta adotar o tratamento de sementes para as semeaduras anteriores a meados de setembro, pois não haverá mais residual do inseticida quando a infestação larval tiver início.

A análise da flutuação populacional também revela que propor o controle químico para eliminar os adultos préhibernantes será pouco eficaz. Primeiramente pela quantidade de indivíduos presentes e pelo período relativamente longo de sua ocorrência (dois meses).


Figura 1. Flutuação populacional média de adultos e larvas de Oryzophagus oryzae em Itajaí, SC, nas safras de 2007/2008 a 2017/2018, e de adultos em Araranguá, SC, nas safras de 2012/2013 a 2015/2016

Figure 1. Mean population fluctuation of adults and larvae of Oryzophagus oryzae in Itajaí, SC, in 2007/08 to 2017/18 seasons and adults in Araranguá, SC, in 2012/13 to 2015/16 seasons.

Nota: A linha de larvas (verde) é do monitoramento executado na safra 1979/80 (SCHMITT \& MIURA, 1981).

Note: The larval line (green) is from monitoring in 1979/80 season (SCHMITT \& MIURA, 1981).

Em segundo lugar porque boa parte dessa população será eliminada naturalmente durante a hibernação, sendo que cerca de $20 \%$ dela retornará apenas na safra seguinte.

Isto posto, a orientação técnica para equacionar o controle químico da bicheira-da-raiz, com base na flutuação populacional do inseto, envolve inicialmente planejar qual estratégia será adotada em caso de necessidade. Há três modalidades de controle químico (HICKEL et al., 2013): tratamento de sementes, pulverização de inseticida e distribuição de inseticida granulado na água de irrigação (embora esta última esteja em desuso). Deve-se lembrar que o residual do tratamento de sementes dura em torno de 40 dias a partir da semeadura.

É importante analisar o histórico de ocorrência de bicheira-da-raiz na propriedade para decidir sobre o tratamento de sementes. Se esse histórico revelar incidência frequente e com danos expressivos, a opção pelo tratamento de sementes pode ser a melhor alter- nativa. Depois, deve-se observar ou monitorar a população de adultos nas quadras a partir de outubro e, se for o caso, decidir pela pulverização de inseticida na época do controle de plantas daninhas. É preciso continuar observando a lavoura e, a partir de meados de outubro, planejar o monitoramento de larvas, iniciando-o por volta de 20 dias após a semeadura (ou da inundação, em caso de plantio em solo seco). Se o monitoramento indicar necessidade, deve-se decidir pela aplicação do inseticida na lavoura.

\section{Estudo de caso 2: percevejo-do- grão, Oebalus spp. (Hemiptera: Pentatomidae)}

A exemplo da bicheira-da-raiz, também há na flutuação populacional do percevejo-do-grão dois momentos importantes na coleta de indivíduos (Figura 2). O primeiro, que se inicia em novembro e se prolonga até meados de dezembro, corresponde à ocorrên- 
cia dos hibernados, ou seja, daqueles adultos que passaram o inverno em diapausa. $O$ segundo momento, durante $o$ mês de fevereiro em Itajaí e de meados de fevereiro ao início de abril em Araranguá, corresponde ao período dos enxames, quando grandes quantidades de indivíduos se dispersam entre as lavouras. Esses enxames podem ser formados só por indivíduos estivais ou por estivais já misturados com indivíduos pré-hibernantes. Esse segundo momento coincide com boa parte das lavouras no estágio mais suscetível ao dano pelo percevejo-do-grão (enchimento de grãos) (Tabela 1).

Em Araranguá, a população de percevejos que ocorre a partir de meados de fevereiro é de 20 a 50 vezes maior que a registrada em Itajaí. Para isso também contribui o cultivo orgânico praticado no Cetrar, que, por florescer mais tarde, atrai toda a população de percevejos das lavouras do entorno já colhidas ou em fase de colheita (HICKEL et al., 2016).

$\mathrm{O}$ primeiro momento revela que o controle do percevejo-do-grão deveria estar focado na época de ocorrência dos hibernados. Os indivíduos hibernados estão debilitados, voam pouco e deixam menos descendentes. Portanto, uma ação de controle sobre essa população eliminaria grande parte da população estival posterior (HICKEL, 2018). O problema é que nessa época as lavouras de arroz não estão atrativas para os hibernados, pois a produção de grãos
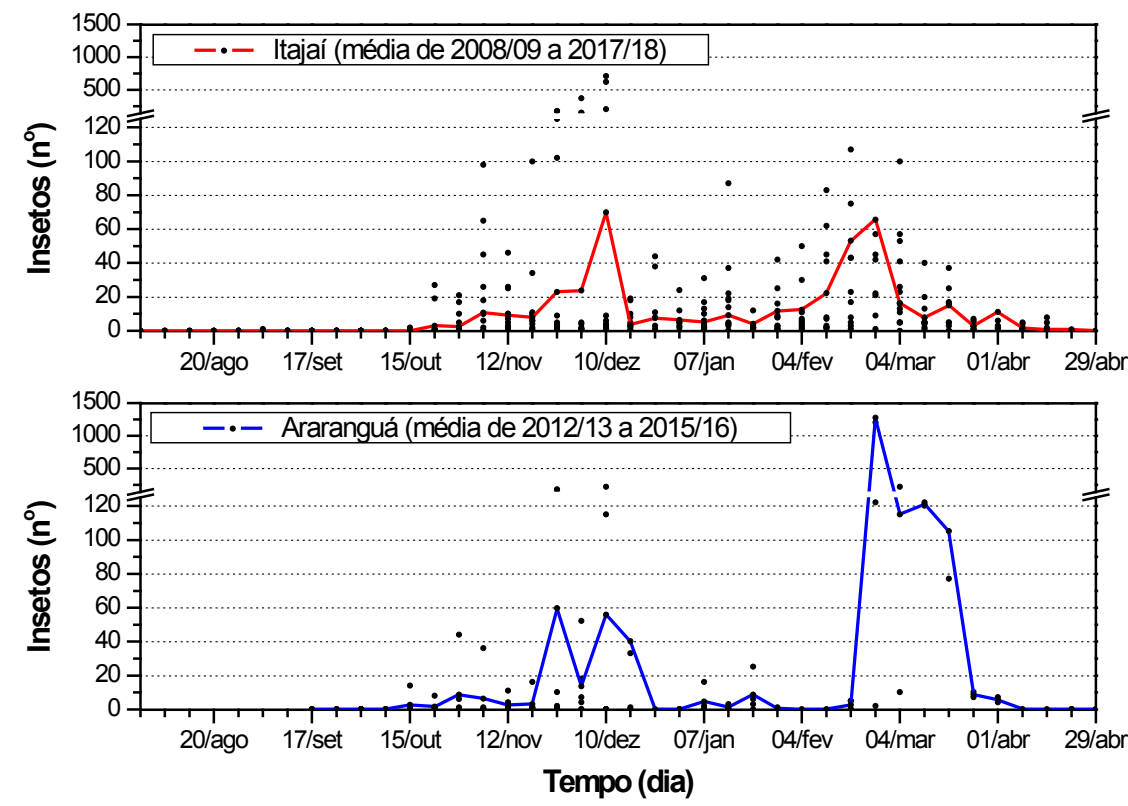

Figura 2. Flutuação populacional média de adultos de Oebalus spp. em Itajaí, SC, nas safras de 2008/2009 a 2017/2018, e em Araranguá, SC, nas safras de 2012/2013 a 2015/2016 Figure 2. Mean population fluctuation of Oebalus spp. adults in Itajaí, SC, in 2008/09 to 2017/18 seasons and in Araranguá, SC, in 2012/13 to 2015/16 seasons

ainda não teve início. Dessa forma, a população de hibernados não adentra as lavouras de arroz.

$O$ segundo momento revela que o controle químico do percevejo-do-grão na lavoura de arroz será problemático. Nessa época de ocorrência dos enxames, o arroz está em enchimento de grãos e pré-maturação, e a aplicação de inseticidas aumenta o risco de contaminação da produção com resíduos de agrotóxicos em função das pulverizações próximas à colheita.

Dessa forma, a orientação técnica para equacionar o controle químico do percevejo-do-grão, com base na flutuação populacional do inseto, envolve planejar e implantar cultivos armadilha para atrair, reter e possibilitar o controle da população de percevejos hibernados (HICKEL, 2018). Na EEI o cultivo armadilha tem sido praticado em quadras pequenas $(0,2 \mathrm{ha})$, com o plantio do cultivar Epagri 106 na primeira semana de setembro, para que este esteja emitindo panículas entre o final de novembro e o início de dezembro.

A partir da emissão de panículas no

Tabela 1. Períodos (em meses) de ocorrência das fases ou etapas do cultivo de arroz irrigado relacionados ao manejo de pragas Table 1. Time (in months) of irrigated rice cropping phases related to pest management

\begin{tabular}{|c|c|c|c|c|c|c|c|c|c|c|}
\hline \multirow[t]{2}{*}{ Fase ou etapa } & \multicolumn{10}{|c|}{ Mês } \\
\hline & Ago. & Set. & Out. & Nov. & Dez. & Jan. & Fev. & Mar. & Abr. & Maio \\
\hline Fase vegetativa & & & & & & & & & & \\
\hline Enchimento de grãos & & & & & & & & & & \\
\hline Colheita & & & & & & & & & & \\
\hline
\end{tabular}


cultivo principal, deve-se iniciar o monitoramento do percevejo-do-grão em intervalo semanal, o que é feito com o uso de rede de varredura, obtendo-se as amostras com 30 golpes de rede em dez pontos, ao acaso, para lavouras de até 5 ha (HICKEL et al., 2016). O controle químico do percevejo-do-grão é indicado quando forem coletados, em média, cinco percevejos por amostra nas duas semanas consecutivas após a floração, ou dez percevejos por amostra nas duas semanas subsequentes (BARRIGOSSI, 2008).

\section{Estudo de caso 3: lagarta- boiadeira, Nymphula spp. (Lepidoptera: Pyralidae)}

A flutuação populacional das mariposas da lagarta-boiadeira segue o padrão de incrementos cumulativos até aproximadamente o final de janeiro, quando passa a sofrer decréscimos cumulativos até o início de março ( $\mathrm{Fi}$ gura 3). Ao contrário da bicheira-da-raiz e do percevejo-do-grão, a lagarta-boiadeira não passa o período de frio em diapausa (HICKEL et al., 2018). Assim, uma população residual persiste nas arrozeiras por quase todo o outono e o inverno. Capins em banhados ou outras áreas alagadiças permitem ao inseto permanecer ativo durante a entressafra do arroz.

Dessa forma, em Itajaí, as mariposas já ocorrem em agosto, bem antes do plantio do arroz. Contudo o crescimento populacional só passa a ser contínuo a partir do primeiro decêndio de outubro. Em Araranguá, a população de mariposas também segue o mesmo padrão, embora com retardo no início do crescimento populacional, que se dá no primeiro decêndio de dezembro. Isso limita o tempo de ocorrência das maiores populações, verificadas somente entre janeiro e fevereiro. Esse retardo também pode resultar do cultivo orgânico praticado em Araranguá, que é semeado mais tarde.

Esse padrão de flutuação popula-
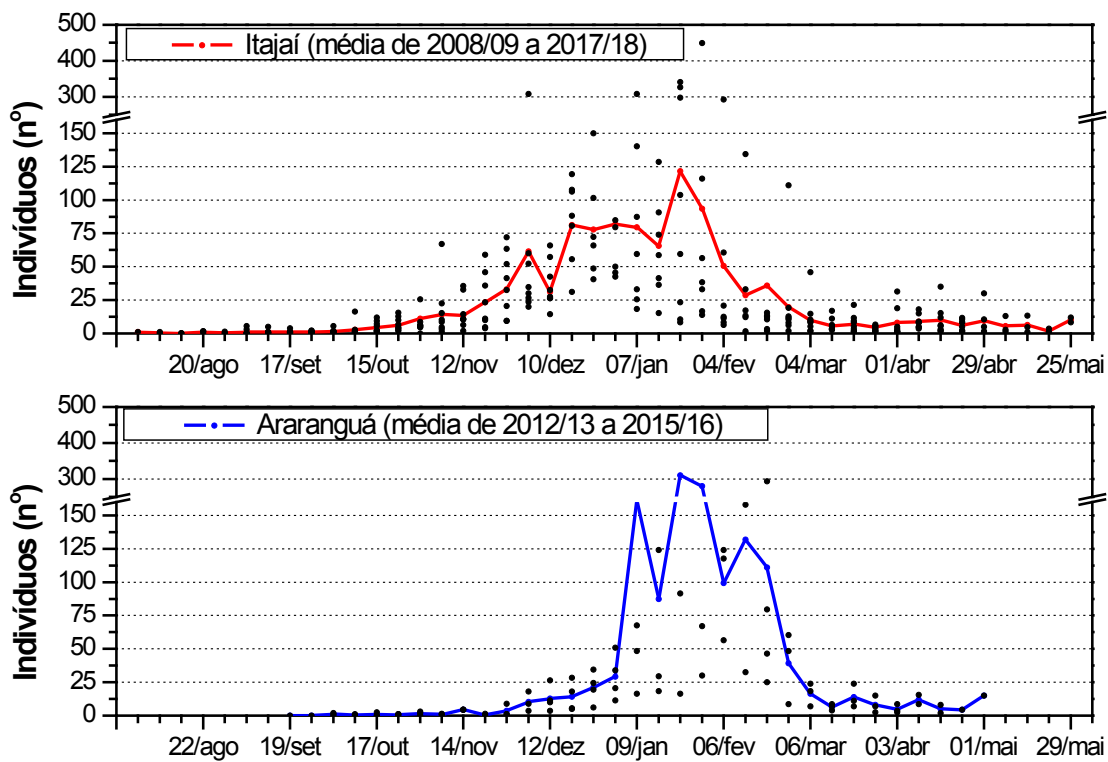

Tempo (dia)

Figura 3. Flutuação populacional média de mariposas de Nymphula spp. em Itajaí, SC, nas safras de 2008/2009 a 2017/2018, e em Araranguá, SC, nas safras de 2012/2013 a 2015/2016

Figure 3. Mean population fluctuation of Nymphula spp. moths in Itajai, SC, in 2008/09 to 2017/18 seasons and in Araranguá, SC, in 2012/13 to 2015/16 seasons

cional revela que, antes do início de novembro, pouco resolve aplicar inseticidas para controle da lagarta-boiadeira, pois haverá poucas mariposas e lagartas para controlar. Já as lavouras semeadas mais tarde (de 15 de novembro em diante) é que estarão sujeitas ao ataque mais intenso da lagarta-boiadeira. A flutuação populacional também revela que as maiores populações de mariposas resultam de populações larvais que se desenvolveram nos meses de novembro e dezembro, quando as plantas de arroz melhor suprem as necessidades nutricionais das lagartas (HICKEL et al., 2018).

Assim, a orientação técnica para equacionar um eventual controle químico da lagarta-boiadeira, com base na flutuação populacional do inseto, envolve inspecionar a lavoura com frequência a partir de novembro e planejar o controle químico, em caso de necessidade, para o período de meados de novembro até o final de dezembro. Em Araranguá, essa opção pelo controle químico, eventualmente, poderia ser postergada para o início de janeiro. Embora não haja estudos para as condições catarinenses, na Ásia (Índia e Filipinas), o controle químico é aplicado quando a contagem de lagartas (cartuchos) em amostras de $0,25 \mathrm{~m}^{2}$ fica entre 3 e 4 lagartas (GODOI \& BORA, 2012).

\section{Considerações finais}

As orientações básicas de controle apresentadas estão relacionadas apenas à decisão pelo controle químico das pragas, que tem grande potencial de causar poluição e desequilíbrios ambientais. No entanto, dentro de um programa de manejo integrado, o controle químico é só mais uma estratégia a ser adotada. Diversas outras podem e devem ser integradas para reduzir a quantidade de indivíduos dessas populações ou seus danos nas lavouras. Uma boa prática de manejo integrado de pragas (MIP) é usar o controle químico apenas como último recurso.

\section{Agradecimentos}

À Fundação de Amparo à Pesquisa e Inovação do Estado de Santa Catarina (Fapesc) e ao Conselho Nacional de De- 
senvolvimento Científico e Tecnológico (CNPq), pelo suporte financeiro ao desenvolvimento dos estudos.

Aos acadêmicos de Agronomia Rafael Ducioni Panato, Débora Dal Zotto, Marino Antônio de Quadros, Luciano da Silva Alves e Sérgio Francisco Bervanger pelo auxílio nas coletas e na triagem de insetos.

\section{Referências}

BARRIGOSSI, J.A. Manejo do percevejo da panícula em arroz irrigado. Santo Antônio de Goiás: Embrapa Arroz e Feijão, 2008. 8p. (Embrapa. Circular Técnica, 79).

GODOI, H.; BORA, D. Spatial distribution of Nymphula depunctalis Guenée larvae (Lepidoptera: Pyralidae), an early vegetative pest of Oryza sativa L. Academic Journal of Entomology, Dubai, v.5, n.1, p.41-46, 2012.
HICKEL, E.R. Cultivo armadilha para manejo integrado do percevejo-do-grão em arroz irrigado. Agropecuária Catarinense, Florianópolis, v.31, n.1, p. 41-44, 2018.

HICKEL, E.R.; HICKEL, G.R.; VILELA, E.F.; SOUZA, O.F.F.; MIRAMONTES, O. Por que as populações flutuam erraticamente? Tantos e tão poucos... E suas implicações no manejo integrado de pragas. Revista de Ciências Agroveterinárias, Lages, v.6, n.2, p. 149-161, 2007.

HICKEL, E.R.; PRANDO, H.F.; EBERHARDT, D.S. $A$ bicheira-da-raiz nas lavouras catarinenses de arroz irrigado: ocorrência, monitoramento e manejo integrado. Florianópolis: Epagri, 2013. 56p. (Epagri. Boletim Técnico, 161).

HICKEL, E.R.; PRANDO, H.F.; EBERHARDT, D.S. Percevejos nas lavouras catarinenses de arroz irrigado: ocorrência, monitoramento e manejo integrado. Florianópolis: Epagri, 2016. 54p. (Epagri. Boletim Técnico, 173).
HICKEL, E.R.; PRANDO, H.F.; EBERHARDT, D.S. Lagartas nas lavouras catarinenses de arroz irrigado: ocorrência, monitoramento e manejo integrado. Florianópolis: Epagri, 2018. 48p. (Epagri. Boletim Técnico, 182).

LOGAN, J.A.; ALLEN, J.C. Nonlinear dynamics and chaos in insect populations. Annual Review of Entomology, Palo Alto, v.37, p.455477, 1992.

POLTRONIERI, A.S.; MONTEIRO, L.B.; SCHUBER, J.M.; CARDOSO, N.A. Conexidade populacional de Grapholita molesta (Busk, 1916) (Lepidoptera: Tortricidae) entre pomares de pessegueiro e macieira. Scientia Agraria, Curitiba, v.9, n.3, p.339-347, 2008.

SCHMITT, A.T.; MIURA, L. Flutuação populacional da bicheira da raiz em arroz irrigado em Itajaí, S.C. In: REUNIÃO DA CULTURA DO ARROZ IRRIGADO, 11., 1981, Pelotas. Anais [...] Pelotas: UEPAE Pelotas, 1981. p.313315 .

\section{Avalie regularmente a qualidade da água que você consome.}

Laboratórios de Análises de Águas:

Fone : (49) 3328-4277

E-mail: cepaf@epagri.sc.gov.br

Chapecó, SC

Fone: (48) 3465-1933

E-mail: eeur@epagri.sc.gov.br

Urussanga, SC

Fone: (49) 3341-5244

E-mail: eei@epagri.sc.gov.br Itajai, SC

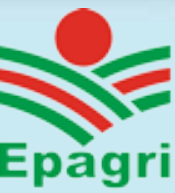

